\title{
Correction: Prevention of obesity in toddlers (PROBIT): a randomised clinical trial of responsive feeding promotion from birth to 24 months
}

Anita Morandi - Mara Tommasi - Francesco Soffiati - Florinda Destro • Laura Fontana - Flavia Grando • Giustina Simonetti - Carmelo Bucolo • Elsa Alberti • Laura Baraldi • Antonietta Chiriacò • Nicoletta Ferrarese • Graziana Frignani - Massimo Pasqualini • Valeria Rossi • Cinzia Siciliano • Anna Maria Zuccolo • Giuliana Matticchio • Valeria Vettori - Daniela Danieli • Loretta Guarda - Maria Iuliano • Francesco Raimo • Stefania Sirpresi • Emanuela Trevisan · Sabrina Vinco • Claudio Maffeis

(c) The Author(s), under exclusive licence to Springer Nature Limited 2020

Correction to: International Journal of Obesity https://doi.org/10.1038/s41366-019-0406-0

In the original Article, Dr. Laura Fontana's name was missing from the author list. This has been corrected
(Dr. Fontana's name and details have been added to the HTML, PDF and XML version of this Article). 